\title{
Do Wages and International Trade Follow an Equilibrium Path?
}

\author{
Manouchehr Mokhtari* \\ University of Maryland, College Park
}

\begin{abstract}
This paper presents an empirical analysis of the factor price equalization theorem (FPE) for 16 OECD countries. The paper demonstrates that the dispersion of wages in the OECD countries follows a non-stationary process. Nonetheless, the wages tend to converge as trade expands. The results also indicate that wage dispersion in the short-run responds in an asymmetric manner to trade expansion depending upon the source of this expansion. In the long-run, estimates show that increases in both exports and imports lead to wage convergence among the OECD countries. This result supports the FPE theorem. [JEL.: FOO,F1, F15, J30, COO, C22]
\end{abstract}

\section{Introduction}

The factor price equalization theorem (FPE) is regarded as one of the major propositions of the Heckscher-Ohlin-Samuelson (H-O-S) model. FPE postulates that, in terms of income distribution, free trade and factor move-

* Address for Correspondence: M. Mokhtari, 1204 Marie Mount Hall, University of Maryland, College Park, MD 20742, U.S.A. Tel: (301) 405-6669, Fax: (301) 314-9161. I would like to thank Janet Wagner and two anonymous referees for helpful comments and suggestions on an earlier version of this paper. An earlier version of this paper was presented at the Cambridge University, Cambridge, UK, September 2-6, 1991. The support of the computing facilities of the Computer Science Center at the University of Maryland - College Park are gratefully acknowledged.

C1995 - Institute for International Economics, Sejong Institution. All rights reserved. 
ment are perfect substitutes. Movement toward free trade, reflecting the presumption of the Heckscher-Ohlin model that trade is caused by difference in factor endowments, should have a significant impact on factor prices. This strongly implies that trade expansion (contraction) should reduce (increase) factor price dispersion across various trading countries. In international trade, many theoretical results depend on the presence or absence of this theorem. For example, see Jones [1956-57], Deardorff [1979], Bhagwati [1972, 1981], Rassekh [1993] and Rassekh and Thompson [1993]. If trade influences factor prices, then trade and factor prices should follow a unique long-run (equilibrium) path. Short-run (transitory) responses of factor prices to trade exposure are also important and should be examined. In this respect, Neary's [1978] work, allowing for factor market distortion and an adjustment mechanism, is insightful because it accounts for some potentially perverse behaviors.

Despite extensive criticism of FPE on the basis of its being inapplicable to the real world, there are three reasons to believe that its implications are powerful enough to lend themselves to empirical modeling and hypothesis testing [Mokhtari and Rassekh, 1987 and 1989]. First, one basic implication of FPE is its relationship to the flow of trade: the higher the level of trade exposure, the narrower the gap among factor prices of trading countries. Second, FPE is relevant to policy analysis if it forms an equilibrium (longrun) relationship with the flow of trade. In the presence of a long-run path, short-run deviations from this path capture dynamic reactions of factor prices to trade movement. Finally, asymmetric or symmetric reaction of factor price dispersion to exports/output and imports/output ratios can be only measured on empirical grounds. Dollar, Wolff, and Baumol [1988, p.44] conclude that the "factor-price equalization through trade in goods, taken as a static result, does not appear to hold across the industrial countries. On the other hand, there appear to be dynamic forces ... that are leading to intertemporal convergence of ... factor prices." 1

The last decade witnessed the proliferation of techniques for testing and

1. It is worth pointingout that Rassekh's [1992] study shows a strong role for the impact of international trade on the convergence of per capita gross domestic products in the OECD countries over the 1950-1985. period. 
modeling economic time series. For example, see Engle and Granger [1987], Baltagi and Mokhtari [1990] and Mokhtari [1992 and 1994]. Nonetheless, the empirical relevance of international trade theories to the real world has been left virtually unexamined. FPE is a prime example of such neglect. This study is an attempt to provide a proper empirical analysis of wage and trade movements using FPE as a conceptual framework.

Given that the theoretical model suggests hypotheses about the potential long-run relationship between wages and trade openness, our empirical analysis of annual observations (i.e., short-run data) sharpens our understanding of the long-run as well as the short-run responses of wages to trade movements. In this regard, a dynamic model of wage convergence through a general to simple modeling strategy is advanced. In particular, Engle and Granger's [1987] econometric techniques for the analysis of time series data are used to properly examine an implication of FPE and to develop a dynamic adjustment model for wage convergence. ${ }^{2}$ While data support the FPE proposition in the long-run, imports and exports exert an asymmetric impact on wage dispersion across OECD countries. Trade exposure has differential short-run and long-run effects on wage convergence across these countries.

Section II introduces the data used in this study, which include measures of wage variation, capital/labor variation, total employment and trade exposure for 16 OECD countries over the 1961-1984 period. Tests for the order of integration (time-series properties) of these variables are also presented. Section III, in addition to presenting some relevant background material, provides an empirical analysis of the long-run relationship between trade exposure and wage conversion across the 16 OECD countries. Section IV provides a dynamic model of wage convergence. Section $\mathrm{V}$ presents some concluding remarks.

2. A further development in the econometric modeling of time-series is Johansen's [1988] maximum likelihood method. This method requires estimation of a (closed) system of (VAR) equations. This is beyond the scope of this paper, as our data set is not large enough relative to the number of variables in the model to get sensible results. 


\section{Time Series Behavior of the Data}

\section{A. Measurements of Wage Dispersion and Trade Exposure}

The dispersion of wages for each year $t(t=1, \ldots T)$ among $n(n=1, \ldots N)$ countries is measured through normalization of the standard deviation of wages by their mean. This variable, the coefficient of variation of wages, is calculated for each year and denoted by $W_{c v, t}$. Manufacturing wages in U.S. dollars divided by the Consumer Price Index (real wages in U.S. dollars) are the basic input to this process. Time paths of $W_{c v, t}$ and other variables (described below) are presented in Figures $1 a$ and $1 b$. Clearly, the downward sloping behavior of the wage dispersion measure indicates that the wage differentials among the OECD countries are being reduced over time.

The importance and movement of trade exposure may be measured in

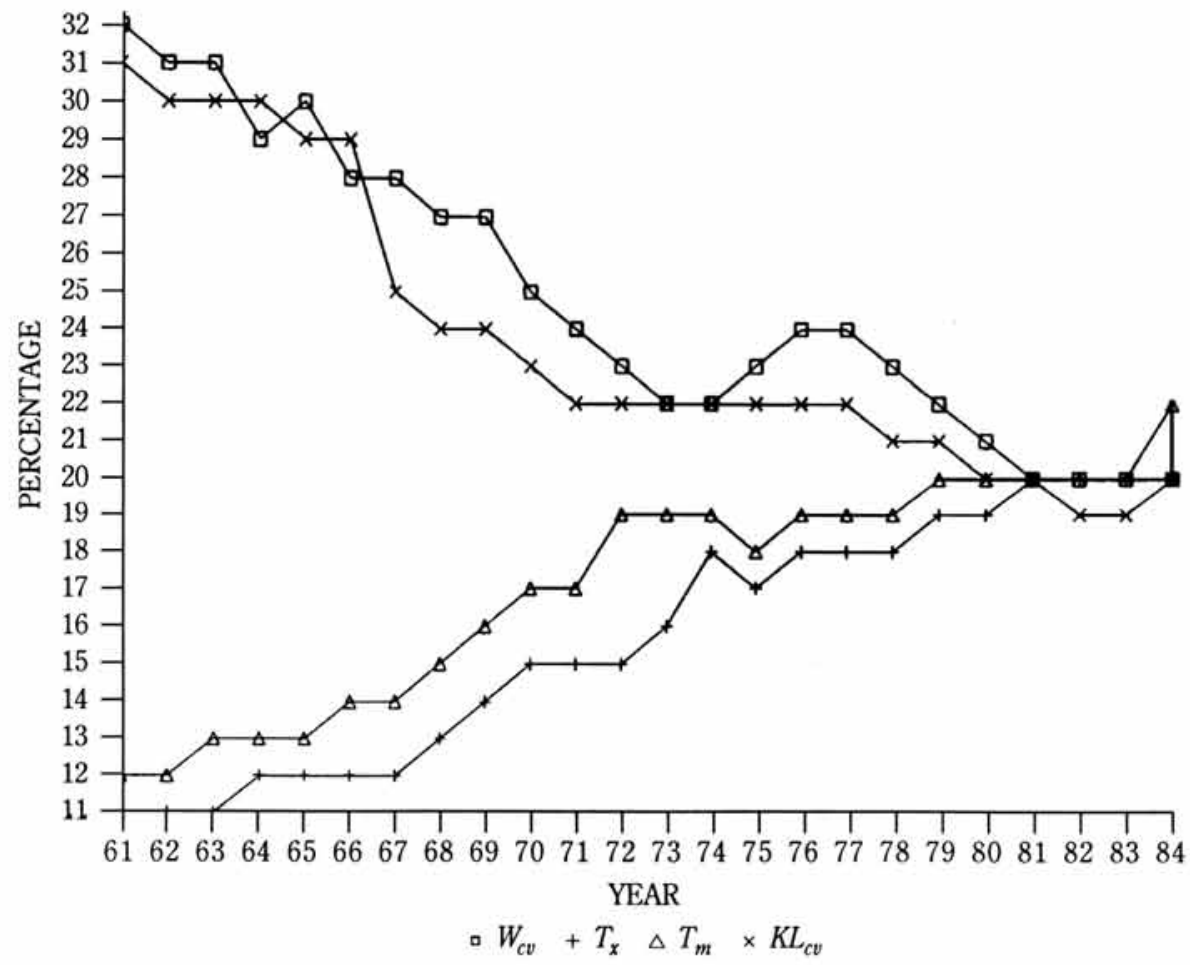

Time Paths of Wage Dispersion, $\boldsymbol{W}_{c v}$ Capital/Labor Dispersion, $K L_{c v}$, and Trade Exposure Indices, $T_{m}$ and $T_{x}$

Figure 1a 
several ways. One would be the sum of imports and exports as a share of total output $\left(T_{x m, t}\right)$. Here, we use the ratio of real imports to total output, $T_{m, t}$, and real exports to total output, $T_{x, t}$. Figures $1 a$ and $1 b$ indicate a tendency toward a global increase in the share of trade out of total output. Even though $T_{m, t}$ and $T_{x, t}$ commence with positive slopes, they possess different characteristics over time and do not provide identical time profiles. Figure 2 , depicting the relationship between $W_{c v, t}, T_{m, t}$ and $T_{x, t}$, is indicative of a nonuniform reaction of wage dispersion to these variables. Overall, downward sloping wage dispersion and upward sloping trade measures support the basic idea behind FPE. Nonetheless, Figure $1 b$ reflects a remarkably complex relationship between our measures of trade exposure and wage dispersion, while controlling for the behavior of the capital/labor $\left(K L_{c v}\right)$ ratio. One may argue that similarity of $K L_{c v}$ among OECD countries implies that this ratio does not exert strong influence on trade or wage convergence. If wages are converging due to the FPE process, factor endowments should

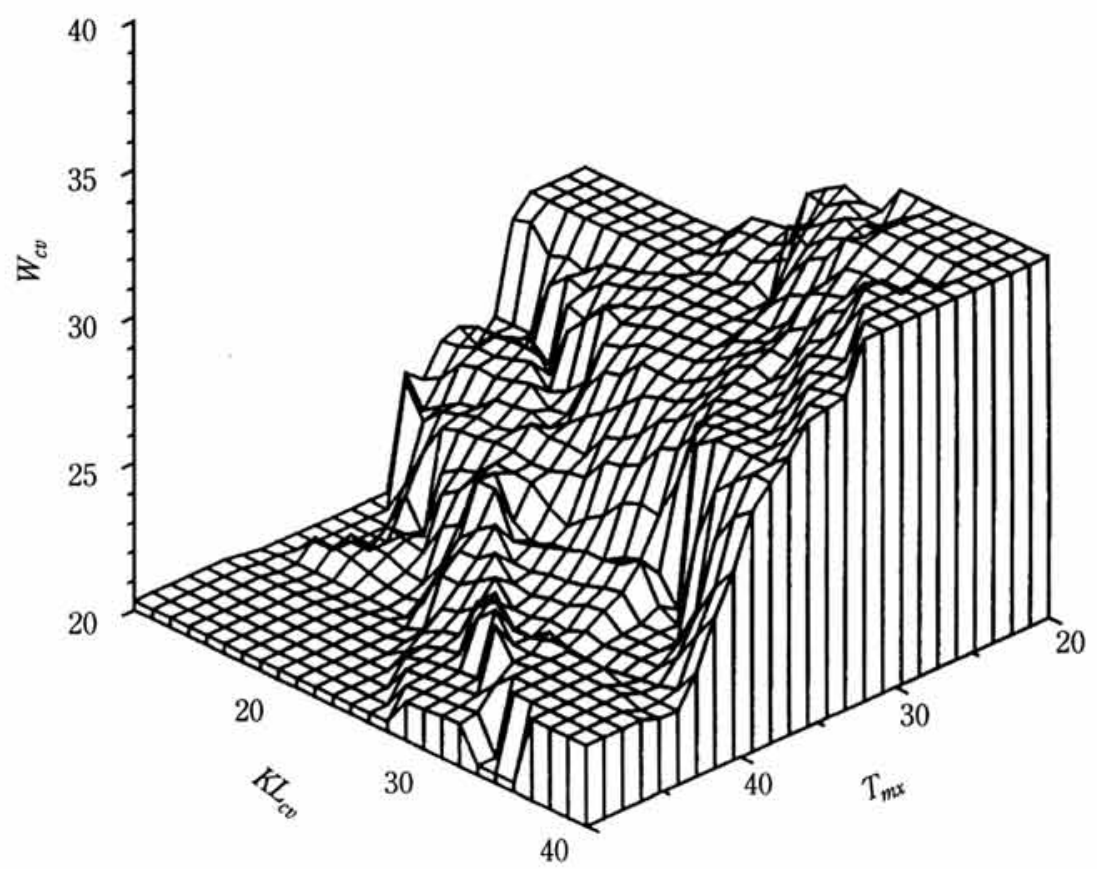

Graph of Wage Dispersion, $W_{c v}$, Capital/Labor Dispersion, $K \mathbf{L}_{c v}$, and Trade Exposure Index, $T_{m x}$

Figure 1b 
make no difference. In particular, factor endowment must lie within the common production cone. Nonetheless, in an empirical study where the real world does not necessarily overlap with the theoretical world, inclusion of $K L_{c v}$ to capture the dispersion in factor endowment is necessary. Clearly, excluding such a variable, when it is statistically significant, leads to serious misspecification and, hence, biased estimates.

Since in the H-O-S framework trade movements are due to differential factor endowments (capital/labor ratio) across countries, a measure of factor endowment dispersion is needed. We divide the stock of capital $(K)$ by employment level in each country at time $t$ (denoted by $E_{i, t}$ ) to obtain a measure of the capital/labor ratio, $K_{i, t} / E_{i, t}$. Then we calculate the coefficient of variation of this variable $\left(K L_{c v, t}\right)$ to capture the dispersion in factor endowments.

As a control variable for full employment, which is generally assumed in

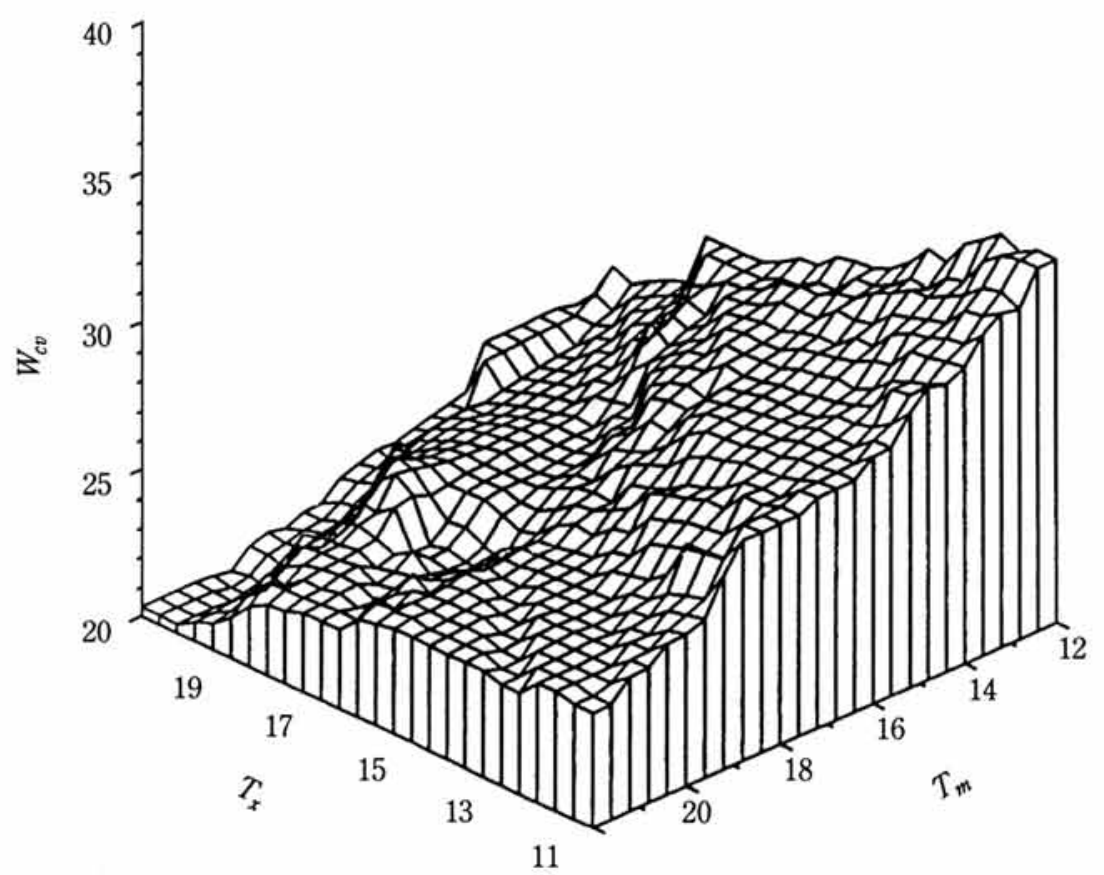

Graph of Wage Dispersion, $W_{c v}$, and Trade Exposure Indices, $T_{m}$ and $T_{x}$ Figure 2 
theories of trade, a measure of total employment $\left(E_{t}\right)$ was also computed. This consisted of the sum of employed workers across all of the $n$ countries in our sample for each year divided by the sum of the labor force across the same number of countries.

\section{B. Testing for Non-Stationarity of the Data}

Inclusion of non-stationary processes in empirical analysis has strong economic and statistical implications. If $W_{c v, t}$ is an integrated (non-stationary) process, then any shock to this variable is going to have a lasting effect. Moreover, inclusion of integrated variables renders the conventional critical values reported for t-tests invalid 〈Philips and Duarluf [1986]〉. Hence, testing for the presence of unit roots (in other words the degree of integratedness) in the time-series of interest is imperative.

The negatively slopped $W_{c v, t}$ implies that wages across countries, though converging, are not equal. Indeed, Katz and Summers [1989, p. 226] found stability in wage differentials across countries and time periods. Accordingly, in testing for the time series property of this variable, an allowance for a drift is made. In particular, we test for the existence of unit roots (non-stationarity) in $W_{c v, t}$ and other variables considered in this study.

To determine the number of unit roots in the logarithmic values of time series in our data set, Sargan and Bahargava's [1983] Cointegrating Regression Durbin-Watson statistic (CRDW), Dickey and Fuller's [1981] t-statistic (DF), and an augmented version of Dickey and Fuller's (ADF) are used. To test for the significance of these statistics, critical values are taken from Sargan and Bahargava [1983] and Fuller [1976, p. 373]. Table 1 presents the estimates of CRDW-, DF- and ADF-statistics for logarithmic values of levels and first changes of variables used in this study. Because DF- and ADF-values for the natural log of all the variables are negative and (in absolute terms) three or higher, $\ln W_{c v, t}, \ln T_{x m, t}, \ln T_{m, t}, \ln T_{x, t}, \ln K L_{c v, t}$ and $\ln E_{t}$ are integrated of the first order, I(1). Hence, their first differences produce stationary time series, $\mathrm{I}(0)$. High values of $\mathrm{CRDW}$ also lend support to the stationarity of first changes in our variables. Below, the proposition that $\ln W_{c v, t}$ and trade variables $\left(\ln T_{x m, t}, \ln T_{m, t}\right.$ and $\left.\ln T_{x, t}\right)$ should follow an equilibrium (cointegrated) path is examined. 
Table 1

The Time Series Properties of the Variables

\begin{tabular}{|l|c|c|c|c|c|c|}
\hline \multirow{2}{*}{ Variable } & \multicolumn{3}{|c|}{ Levels } & \multicolumn{3}{c|}{ First Changes } \\
\cline { 2 - 7 } & CRDW & DF & ADF & CRDW & DF & ADF \\
\hline $\ln W_{c v}$ & 0.0 & -1.0 & -1.0 & 1.2 & -3.1 & -4.7 \\
\hline $\ln K L_{c v}$ & 0.0 & -1.4 & -1.1 & 1.9 & -4.6 & -3.3 \\
\hline $\ln T_{x m}$ & 0.0 & -0.9 & -0.7 & 2.2 & -5.3 & -3.2 \\
\hline $\ln T_{x}$ & 0.0 & -0.6 & -0.7 & 2.0 & -4.9 & -3.4 \\
\hline $\ln T_{m}$ & 0.0 & -1.1 & -0.9 & 2.1 & -5.0 & -3.0 \\
\hline $\ln E$ & 0.1 & 0.1 & -0.9 & 1.3 & -3.3 & -3.8 \\
\hline
\end{tabular}

\section{Do Wages and International Trade Follow an Equilibrium Path?}

\section{A. A Two-Step Procedure}

An important reason for the lack of rigorous and proper empirical analysis of the implications of FPE has been its underlying assumptions, which have led well-known international trade scholars to find FPE intractable from an empirical standpoint 〈Caves [1960]). On the relevance of the FPE theorem to the real world, Samuelson [1949, p.881] expresses his doubts and hopes as follows: "I cannot pretend to present a balanced appraisal of the bearing of this analysis upon interpreting the actual world ... but ... strong simple cases often point the way to an element of truth present in a complex situation." The recent survey article of Rassekh and Thompson [1993] contains relevant references.

Engle and Granger [1987] provide appropriate techniques that allow for estimation, testing and modeling of various economic variables presumed to follow an equilibrium (long-run) path with each other. These techniques allow us to test economic propositions about the behavior of variables in equilibrium, while allowing for the short-run dynamics (adjustments) suggested by the data. Since economic theories imply that variables following an equilibrium (cointegrated) path should not diverge from each other by too great an extent, cointegration techniques can be employed to test, estimate and model the relationship between trade movements and wages across various countries. In this paper, the theory of cointegrated variables 
is used to test whether the dispersion of wages across sixteen OECD countries during the 1961-1984 period followed an equilibrium (a cointegrated) path with the measures of trade exposures.

Since non-stationary variables following a unique path with each other have an Error Correction Representation (Granger's Representation Theorem), Engle and Granger suggest two-steps for modeling, estimation, and testing. First, after establishing that two variables are integrated of the first order (i.e, their first difference is stationary), an equilibrium model by way of a regression on the levels of variables of interest is formed. Existence of such a regression in levels implies that variables of interest follow an equilibrium path. Stationarity of estimated residuals from this regression implies that estimated coefficients (equilibrium parameters) are unique. In fact, Stock [1987] shows that these estimated coefficients are super-consistent. Second, the lagged residuals from this regression are used as the error correction term in a standard ECM model. A significant error correction term would support the validity of ECM and, therefore, the equilibrium model. Moreover, the $t$-test on the error correction term has been shown to be a more viable test of the cointegration of included variables than either the ADF- or CRDW-statistics 〈Banerjee, et al., [1986]).

\section{B. Estimating an Equilibrium Path}

On practical grounds, Ethier [1988, p. 109] takes FPE to mean that: "Free international trade between two countries will cause factor prices in the countries to become more equal." Clearly, delicate properties of the production functions, transportation costs, tariffs, asymmetric diffusion of technology among countries, imperfect competition, factor endowments being too far apart, deviation from constant return to scale, higher numbers of factors than goods, increases in non-traded goods, and other obstructions to international trade justify the position of Ethier and other trade scholars to expect convergence rather than equality. Hence, in the presence of an integrated process for the trade volume among nations over time, convergence of wages toward an equilibrium path is what we should look for. Recent attempts at lowering trade barriers, in the European Economic Community for example, put this proposition at the forefront of empirical analysis 
〈Tovias [1982]〉. For our analysis, Ethier's definition provides the context in which we will conduct our empirical analysis of the above proposition. Accordingly, a static functional relationship that allows for the effect of trade expansion on the dispersion of wages among OECD countries, while controlling for the impact of other variables, is estimated:

$$
\begin{aligned}
& \ln W_{c v, t}=-1.2+0.35 \ln K L_{c v, t}+0.81 \ln E_{t}-0.41 \ln T_{m x, t}+e_{t} \\
& \rho=0.6 D F=-3.5 A D F=-3.0 R^{2}=.95
\end{aligned}
$$

where, $e_{t}$ is the error term and $\rho$ is the first-order coefficient of autocorrelation among the disturbances. ${ }^{3}$ Since the variables in (1) are nonstationary, the Gauss-Markov theorem does not hold and standard errors of the parameter estimates following a nonstandard distribution are not suitable for inference; hence, we are not reporting these statistics. The high R-squared on the reported cointegrated regression can be taken as an indication that spurious regression is not a problem. Reported $D F$ and $A D F$ values support (1) as a cointegration regression. However, decomposing $T_{m x, t}$ into its components, i.e., relaxing the parameter restriction on $T_{m, t}$ and $T_{x, t}$, provides remarkable insight into the impact of trade exposure on wage convergence. Inclusion of $T_{m, t}$ and $T_{x, t}$ instead of $T_{m x, t}$ yields:

$$
\begin{aligned}
& \ln W_{c v, t}=-1.5+0.34 \ln K L_{c v, t}+0.97 \ln E_{t}-0.14 \ln T_{x, t}-0.27 \ln T_{m, t}+e_{t} \\
& \rho=0.5 \quad D F=-3.6 \quad A D F=-3.0 \quad R^{2}=0.95
\end{aligned}
$$

Reported tests of the unit roots $(D F$ and $A D F)$ for both (1) and (2) reject the null hypothesis of no-cointegration (non-stationarity) in the residuals. This indicates that our coefficient estimates are unique, supporting our estimated regression as an equilibrium (long-run) relationship. Since standard errors (and, therefore, $t$-tests) of the parameter estimates that include integrated variables are shown to follow a non-standard distribution, and hence, are not suitable for inference, we are not reporting these statistics. Nonetheless, Stock [1987] proves that OLS estimates obtained by performing a coin-

3. Since high values of $\rho$ (as reported here) indicate significant loss (more than $50 \%$ ) in the power of CRDW-test, we rely on DF- and ADF tests for inference about cointegrated regressions. For a comprehensive analysis of the CRDW-test, see Sargan and Bhargava [1983]. 
tegrated regression converge to their true values at a faster rate than otherwise. In particular, our coefficient estimates have a bias of order $T^{-1}$ rather than order of $T^{-1 / 2}$. Hence, the estimates are super-consistent. For further examination and an excellent treatment of regression models with non-stationary regressors see West [1988].

Our primary focus will be on (2), as it is more revealing of the underlying process causing wage dispersion (convergence) across the OECD countries. The signs of the coefficients are of primary interest. Similarly, a positive coefficient estimate on $\ln E_{t}$ shows that the higher the rate of employment, the higher the wage dispersion among OECD countries. Three theories can explain this phenomenon. First, a higher employment rate may imply that a more heterogeneously productive labor force is in the market now and, hence, a wider range of wages is being offered and taken. Second, a higher employment rate may also reflect higher opportunity cost in home and foreign countries for the workers who would otherwise have been mobile (potentially, going to another country). Third, if a higher level of employment is due to the expansion of the nontraded goods industries (e.g., service industry) then the positive cofficient estimate on $\ln E_{t}$ supports the results of Deardorff and Courant [1990], who show that the likelihood of the FPE theorem holding declines as the number of nontraded goods increases.

Our estimated parameter for the total level of trade exposure $\ln T_{x m, t}$ and its components $\left(\ln T_{x, t}\right.$ and $\left.\ln T_{m, t}\right)$ all have obtained their long-run expected negative sign. Negative elasticities of the coefficient of variation of wages $\ln W_{c v, t}$ with respect to our measures of trade exposure, range between -0.14 and -0.41 . The reported coefficient estimates of export and import ratios are consistent with our findings in Figure 2. The differential slopes of $\ln T_{x, t}$ and $\ln T_{m, t}$ support disaggregation of $\ln T_{x m, t}$ to its components. Although reported cointegrated regressions and the expected negative signs on trade exposure variables support FPE, further insight can be gained by applying a dynamic modeling framework.

\section{A Dynamic Model of Wage Convergence}

Time series observations used in estimating the long-run (theoretical) relationships, i.e., equation (2), are the outcome of the short-run transac- 
tions among economic agents or countries. Nonetheless, parameter estimates in the cointegrated regressions are shown to be consistent estimates of true equilibrium parameters; hence, capturing long-run reactions of the dependent variable to independent variables. These parameter estimates of cointegrated regressions provide a unique path from which the economic system should not significantly depart. In this context, a complete model of wage convergence offers an opportunity for an empirical analysis of FPE. Such an analysis will be more useful than the static regression tests of cointegration, which are obtained by using the estimates of equations (1) and (2) 〈Jenkinson [1986]〉.

Hendry's general to simple dynamic modeling methodology [Gilbert, 1986] and Granger's representation theorem, proving that cointegrated variables have an error correction representation, provide the framework for a proper analysis of FPE. The above two step procedure is consistent with Hendry's methodology that lets the short-run reactions around the long-run attractor be determined by the data. Accordingly, we estimate an over-parameterized model with the contemporaneous and lagged changes of the dependent and explanatory variables in (2). Additionally, estimated lagged residuals from the cointegrated regression, (2), are added as an explanatory variable. OLS estimates of our over-parameterized model are as follows:

$$
\begin{aligned}
& \Delta \ln W_{c v, t}=0.00+0.16 \Delta \ln K L_{c v, t}-0.08 \Delta \ln K L_{c v, t-1}+0.37 \Delta \ln E_{t}
\end{aligned}
$$

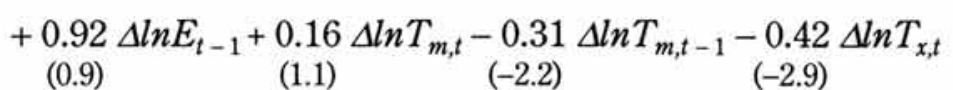

$$
\begin{aligned}
& +\underset{(1.6)}{0.38} \Delta \ln T_{x, t-1}+\underset{(3.5)}{0.64} \Delta \ln W_{c v, t-1}-\underset{(-4.5)}{0.57} E C_{t-1}+u_{t} \\
& R^{2}=0.68 \ln L=59.7 \quad D W=2.3 \quad \eta_{1}(1)=3.6 \quad \eta_{2}(1)=0.3 \quad \eta_{3}(2)=2.6
\end{aligned}
$$

where, $u_{t}$ is the white noise error, $\Delta^{i}=(1-L)^{i}$ and $L$ is the lag operator, $E C_{t-1}$ is the lagged residuals from (2), and $l n L$ is the maximized value of the log of likelihood function. Values in parentheses under the coefficient estimates are heterscadacity-consistent $t$-values; see White [1980]. $D W$ is the conventional Durbin-Watson statistic for detecting serial correlation among the disturbances. $\eta_{1}(1)$ is the Bruesch-Godfrey [1978] Lagrange Multiplier test for detecting the first order serial correlation among the residuals; $\eta_{2}(1)$ is the 
test for the autoregressive conditional heterscadacity-effect (ARCH effect) among the residuals; see Engle [1982]. Both $\eta_{1}(1)$ and $\eta_{2}(2)$ have central chisquare distributions with one degree of freedom. For testing the normality of the residuals, Jarque and Bera's [1980] Lagrange Multiplier test, $\eta_{3}(2)$, is reported; this has a central chi-square distribution with two degrees of freedom. The tests reported above do not indicate any shortcomings.

After an iterative simplification, reparameterization and testing 〈Hendry, Pagan and Sargan [1984]), we obtained the following error correction model:

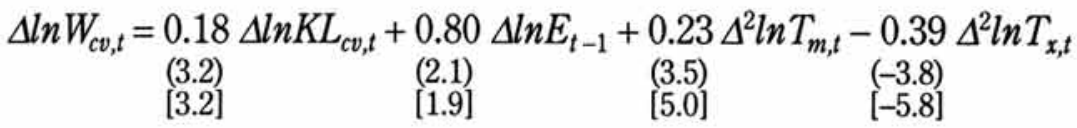

$$
\begin{aligned}
& +0.64 \Delta \ln W_{c v, t-1}-0.57 E C_{t-1}+\mu_{t} \\
& \begin{array}{ll}
(8.2) & (-6.9) \\
{[6.5]} & {[-8.2]}
\end{array} \\
& R^{2}=0.67 \ln L=59.2 \quad D W=2.2 \eta_{1}(1)=1.5 \eta_{2}(1)=0.4 \\
& \eta_{3}(2)=3.75 \xi_{1}(5,16)=0.14 \quad \xi_{2}(5,11)=0.12
\end{aligned}
$$

which is a more parsimonious representation than (3), since it has five parameters fewer than (3). ${ }^{4}$ This is supported by the reported F-test, $1(5,16)$, at the $5 \%$ level of significance. Reported statistics support (4) as a viable model for inference. An F-test of the imposed parameter restrictions, nested in the ECt- 1 term, supports the ECM specification, see $\xi_{2}(5,11)$. We estimate (4), with the $\ln W_{c v, t-1}, \ln K L_{c v, t-1}, \ln E_{t-1}, \ln T_{x, t-1}$ and $\ln T_{m, t-1}$ replacing the $E C_{t-1}$ term as the unrestricted model. The results of the F-test, $\xi_{2}(5,11)$, at $5 \%$ level of significance, support our model. Moreover, as a check on the validity of the t-ratios of the EC terms, a series of bootstrap experiments with 1000 repetitions was conducted 〈Efron and Tibshirani [1986]〉. The medians of the obtained $t$-ratios are reported in the brackets. These values support our model, in general, and the error correction term, in particular. In this respect, the inverse relationship between wage dispersion and trade exposure may be considered as an attractor from which open economies cannot devi-

4. Note that $\Delta \ln X_{t}=(1-L) \ln X_{t}=\ln X t-\ln X_{t-1}$ where, $L$ is the lag operator, represents growth rate in $X_{t}$. Similarly, $\Delta^{2} \ln X_{t}=(1-L)^{2} \ln X_{t}=\left(1-2 L+L^{2}\right) \ln X_{t}=\ln X_{t}-2 \ln X_{t-1}+\ln X_{t-2}=\Delta \ln X_{t}-\Delta \ln X_{t-1}$ represents acceleration in $X_{t}$. 
ate too far over time.

The most remarkable finding is the asymmetric reaction of the growth in wage dispersion to acceleration in trade exposure indices. The reported coefficient estimates in (4) capture short-run responses (impact elasticities) of the wage dispersion measure $\ln W_{c v, t}$ to the trade exposure measures $\ln T_{x, t}$ and $\ln T_{m, t}$. Accordingly, in the short-run, acceleration in imports of goods and services (relative to output) leads wages to diverge. This is opposite to the long-run relationship (2). On the other hand, acceleration of exports of goods and services (relative to output) leads wages to converge. Without a complete dynamic specification, we would not have been able to account for these empirical findings. Therefore, different measures of trade exposure (e.g., imports/output and exports/output ratios) should simultaneously be included in dynamic (and short-run) models of wage determination. ${ }^{5}$

An examination of the coefficients in (4) reveals important but silent features of the data analyzed in this paper. Estimated coefficients of $\Delta \ln K L_{c v, t}$ and $\Delta \ln E_{t}$ suggest that growth in dispersion of production technology and in employment leads international wages to diverge. Similarly, a positive coefficient estimate on $\Delta l n W_{c v, t-1}$ indicates that, ceteris paribus, the higher the rate of wage dispersion in the past, the higher the rate of wage dispersion will be in the present. This may indicate the natural tendency of wages to diverge when strong economic forces (e.g. trade exposure indices) are kept constant. This is not surprising since, in the absence of trade and factor mobility, wages reflect relative scarcity of labor within each country. Overall, short-run elasticities in (4), apart from those of $\Delta^{2} l n T_{x, t}$ and $E C_{t-1}$, are indicative of wage divergence among the OECD countries; hence, the long-run convergence of wages can be only attributed to significant trade exposure in the long-run.

\section{Conclusion}

Using the analysis of time series, we demonstrate that the dispersion of wages in the OECD countries follows a non-stationary (integrated) process.

5. Inclusion of proxies such as the price of exports alone does not seem to capture the complex dynamics that drive wage movement across countries. 
Nonetheless, the wages in the OECD countries tend to converge as international trade expands. Tests indicate that both wage dispersion among the OECD countries and international trade follow an equilibrium (cointegrated) path. The results also indicate that international wage dispersion in the short-run responds asymmetrically to trade expansion depending upon the source of this expansion. Estimation of an error correction representation shows that, in the short-run, an increase in the imports/output ratio leads to an increase in wage dispersion, while a similar increase in the exports/output ratio leads to a decrease in wage dispersion. Therefore, different measures of trade exposure (e.g., imports/output and exports/output ratios) should simultaneously be included in the dynamic (and short-run) models of wage determination. However, our long-run estimates show that, in general, increases in both exports and imports, relative to output, lead to wage convergence among the OECD countries, supporting the Factor Price Equalization theorem.

\section{References}

Baltagi, Badi, and Mokhtari, Manouchehr [1990], "Inter-country Evidence on the Performance of the Simple Error Correction Mechanism Model of Consumption," Empirical Economics 15; pp. 303-314.

Banerjee, Anindya, et al. [1986], "Exploring Equilibrium Relationships in

Econometrics Through Static Models: Some Monte Carlo Evidence,"

Oxford Bulletin of Economics and Statistics 48; pp. 253-277.

Bhagwati, Jagdish N. [1972], "The Heckscher-Ohlin Theorem in the Multi-

Commodity Case," Journal of Political Economy 80; pp. 1052-1055.

Bhagwati, Jagdish N. [1981], International Trade: Selected Readings, Cambridge: The MIT Press.

Breusch, T. S. [1978], "Testing for Autocorrelation in Dynamic Linear Models," Australian Economic Papers 17; pp. 334-355.

Caves, Richard E. [1960], Trade and Economic Structure, Cambridge: Harvard University Press.

Deardorff, Alan V. [1979], "Weak Links in the Chain of Comparative Advantage," Journal of International Economics 9; pp. 197-209.

Deardorff, Alan V. and Courant P. N. [1990], "On the Likelihood of Factor 
Price Equalization With Nontraded Goods," International Economic Review 31; pp. 589-596.

Dickey, David A. and Fuller, Wayne A. [1981], "The Likelihood Ratio Statistics for Autoregressive Time Series with a Unit Root," Econometrica 49; pp. 1057-72.

Dollar, David, Wolff, Edward N. and Baumol, William J. [1988], "The FactorPrice Equalization Model and Industry Labor Productivity: An Empirical Test Across Countries," in Empirical Methods for International Trade, R. C. Feenstra (ed.), Cambridge: MIT Press; pp. 23-47.

Efron, Bradly and Tibshirani, R. [1986], "Bootstrap Methods for Standard Errors, Confidence Intervals, and Other Measures of Statistical Accuracy," Statistical Science 1; pp. 54-77.

Engle, Robert F. [1982], "Autoregressive Conditional Heterscadacity with Estimates of Variance of United Kingdom Inflations," Econometrica 50; pp. 987-1008.

Engle, Robert F. and Granger, Clive W. J. [1987], "Co-Integration and Error Correction: Representation, Estimation, and Testing," Econometrica 55; pp. 251-276.

Ethier, Wilfred J. [1988], Modern International Economics, New York: W.W. Norton \& Company.

Fuller, Wayne A. [1976], Introduction to Statistical Time Series, New York: Wiley.

Gilbert, Christopher L. [1986], "Professor Hendry's Econometric Methodology," Oxford Bulletin of Economics and Statistics 48; pp. 283-307.

Godfrey, L. G. [1978], "Testing Against General Autoregressive and Moving Average Error Models When the Regression Includes Lagged Dependent Variables," Econometrica 46; pp. 1293-1302.

Hendry, David F., Pagan, Adrian R., and Sargan, J. Denis [1984], "Dynamic Specification," in Z. Griliches and M. D. Intriligator (eds.) Handbook of Econometrics, Vol. 2, Amsterdam: North-Holland, pp. 1023-1100.

Jarque, Carlos M. and Bera, Anil K. [1980], "Efficient Tests for Normality, Homoscedasticity and Serial Independence of Regression Residuals," Economics Letters 6; pp. 255-259.

Jenkinson, T. J. [1986], "Testing Neo-Classical Theories of Labour Demand: An Application of Cointegration Techniques," Oxford Bulletin of Eco- 
nomics and Statistics 48; pp. 241-251.

Johansen, S. [1988], “Statistical Analysis of Cointegration Vectors," Journal of Economic Dynamics and Control, 12; pp. 231-254.

Jones, Ronald W. [1956-57], "Factor Proportions and the Heckscher-Ohlin Theorem," Review of Economic Studies 24; pp. 1-10.

Katz, Lawrence F. and Summers, Lawrence H. [1989], "Industry Rents: Evidence and Implications," in Brookings Papers on Economic Activity: Microeconomics 1989, The Brookings Institution, Washington D.C.

Mokhtari, Manouchehr and Rassekh, Farhad [1987], "Wage Movements and Trade Openness in the OECD," manuscript, Department of Economics, University of Houston.

Mokhtari, Manouchehr and Rassekh, Farhad [1989], "Tendency Towards Factor Price Equalization in the OECD," The Review of Economics and Statistics 71; pp. 636-642.

Mokhtari, Manouchehr, [1992], "An Alternative Model of U.S. Clothing Expenditure,” Journal of Consumer Affairs 26; pp. 305-323.

Mokhtari, Manuchehr [1994], "Testing for Liquidity Constraints Among Households: An International Analysis," Empirical Economics 19; pp. 709-715.

Neary, J. Peter [1978], "Short-Run Capital Specifity and the Pure Theory of International Trade," Economic Journal 88; pp. 488-510.

Phillips, Peter C. B. and Durlauf, Steven N. [1986], "Multiple Time Series Regression with Integrated Processes," Review of Economic Studies 53; pp. 473-495.

Rassekh, Farhad [1992], "The Role of International Trade in the Convergence of Per Capita GDP in the OECD: 1950-85," International Economic Journal 6.

Rassekh, Farhad [1993], "International Trade and the Relative Dispersion of Industrial Wages and Production Techniques in 14 OECD Countries, 1970-1985," Open Economies Review 4; pp. 325-344.

Rassekh, Farhad and Thompson, H. [1993], "The Factor Price Equalization Theorem: Theory and Evidence," Journal of International Economic Integration 8; pp. 1-32.

Samuelson, Paul A. [1949], "International Factor Price Equalization Once Again,” Economic Journal 59; pp. 869-885. 
Sargan, J. Denis and Bhargava, Alok [1983], "Testing Residuals from Least Squares Regression for Being Generated by the Gaussian Random Walk," Econometrica 51; pp. 153-74.

Stock, J. H. [1987], "Asymptotic Properties of a Least Squares Estimator of Cointegrating Vectors," Econometrica 55; pp. 1035-1056.

Tovias, Alfred [1982], "Testing Factor Price Equalization in the EEC," Journal of Common Markets Studies 20; pp. 375-388.

West, Kenneth D. [1988], “Asymptotic Normality, When Regressors Have A Unit Root," Econometrica 56; pp. 1397-1417.

White, Halbert [1980], "A Heteroscedastic-Consistent Covariance Matrix Estimator and a Direct Test for Heterscadacity," Econometrica 48; pp. 421-448. 